\title{
Imaging and pathological findings of intramedullary inflammatory pseudotumour in a miniature dachshund: a case report
}

\author{
Masamichi Yamashita', Tomohiro Osaki ${ }^{1 *}$ D, Yusuke Murahata', Yuji Sunden', Rinko Morita², \\ Tomohiro Imagawa ${ }^{1}$ and Yoshiharu Okamoto ${ }^{1}$
}

\begin{abstract}
Background: Inflammatory pseudotumours (IPTs) are distinctive lesions consisting of myofibroblastic spindle cells and a variety of inflammatory cells. The aetiology of IPTs is unknown. Reports of IPTs in veterinary medicine have been scarse. Moreover, only one case of intradural extramedullary IPT has been previously reported. In this report, we introduce the first known case of canine IPT, which occurred in the parenchyma of the spinal cord.

Case presentation: A 10-year-old female Miniature Dachshund presented with a 2-month-long history of progressively worsening ataxia and tetraparesis. Neurological examination was consistent with a lesion involving the cervical spinal cord. Magnetic resonance imaging revealed an intradural space-occupying lesion in the region of the fourth cervical vertebra. Dorsal laminectomy and resection of the mass were performed. Histopathological examination revealed the proliferation of immature spindle cells (fibroblasts/myofibroblasts and glial cells) and a highly cellular mixture of neutrophils, macrophages and lymphocytic cells. The mass was located in the parenchyma of the spinal cord and was diagnosed as an IPT occurring in the parenchyma of the spinal cord. No causative pathogen was detected. The dog's symptoms improved, during the first month after surgery. However, neurological symptoms, such as laboured breathing and dysuria, subsequently worsened and the dog died 42 days after surgery.

Conclusions: The present study describes a canine case of IPT occurring in the parenchyma of the spinal cord. The diagnosis and determination of the site of the mass was difficult solely based on preoperative imaging in the present case. The outcome of this case was poorer than that observed in cases of canine extramedullary IPT and human intramedullary IPT, in which the patients exhibited recovery. The prognosis after surgical resection cannot be decided from the present case alone. However, patients should be monitored for potential serious complications and recurrence.
\end{abstract}

Keywords: Canine tumour, Spinal cord parenchyma, Paresis, Pseudotumour

\section{Background}

Inflammatory pseudotumours (IPTs) are distinctive lesions, composed of myofibroblastic spindle cells accompanied by an infiltration of inflammatory cells such as plasma cells, lymphocytes, and eosinophils $[1,2]$. The aetiology of IPTs, which can occur throughout the body, is unknown $[1,3]$.

\footnotetext{
* Correspondence: tosaki@muses.tottori-u.ac.jp

${ }^{1}$ Joint Department of Veterinary Clinical Medicine, Faculty of Agriculture,

Tottori University, 4-101 Koyama-cho Minami, Tottori, Tottori 680-8553, Japan Full list of author information is available at the end of the article
}

IPTs are very rare, and reports of their occurrences are limited in veterinary medicine [4-8]. Notably, only one case of intradural extramedullary IPT has been reported [2]. There have been some reports of intra- and extramedullary spinal IPTs in humans [9-12]. The prognosis after surgical resection is favourable for spinal IPTs. A lesion was located from C2 to T10 in a case of human intramedullary IPT, and the outcome was good after complete resection [9]. A case of a canine intradural extramedullary IPT lesion at T13/L1 exhibited a good outcome after resection [2].

(c) The Author(s). 2019 Open Access This article is distributed under the terms of the Creative Commons Attribution 4.0 International License (http://creativecommons.org/licenses/by/4.0/), which permits unrestricted use, distribution, and reproduction in any medium, provided you give appropriate credit to the original author(s) and the source, provide a link to the Creative Commons license, and indicate if changes were made. The Creative Commons Public Domain Dedication waiver (http://creativecommons.org/publicdomain/zero/1.0/) applies to the data made available in this article, unless otherwise stated. 
In this report, we describe the first known canine case of an IPT occurring in the parenchyma of the spinal cord.

\section{Case presentation}

A 10-year-old female Miniature Dachshund weighing $6.46 \mathrm{~kg}$ presented with a 2-month history of progressive thoracic and pelvic limb paresis. The dog underwent three surgical procedures to reposition an inguinal hernia, resect a mammary gland tumour and spay the animal, and resect a mass that was on the surface of the face and not diagnosed by pathological examination by ablation. Administration of prednisolone $1 \mathrm{mg} / \mathrm{kg}$ (Nippon Zenyaku Kogyo) daily and stabilization of the neck with a neck collar temporarily resolved the animal's ataxia, although the paresis continued to progress.

The neurological exam revealed a decrease in the right thoracic limb postural reaction and normal or slightly slow left thoracic limb and bilateral pelvic limb postural reactions. Right thoracic limb spinal reflexes were absent, and left thoracic limb spinal reflexes were decreased. Pelvic limb spinal reflexes were present or exaggerated. Neck pain was also identified without palpation.

A complete blood cell count and serum biochemistry revealed mild increase in serum alanine aminotransferase, a moderate increase in serum alkaline phosphatase, and a mild increase in serum $\gamma$-glutamyl transferase. Magnetic resonance (MR) imaging (0.3-T AIRIS Vento, HITACHI, Inc.; Tokyo, Japan) revealed a mass in the dorsal spinal cord at the fourth cervical vertebral (C4) level and a large, hyperintense T2-weighted imaging (WI) lesion from $\mathrm{C} 2$ to C6. The mass was hypointense on T2-WI, isointense on T1-WI, hypo- to isointense on fluid attenuated inversion recovery imaging, and strongly and homogenously enhanced on T1-WI postcontrast imaging following intravenous administration of a paramagnetic contrast agent (gadoteric acid; Magnevist, Bayer Yakuhin Ltd., Japan) (Fig. 1). Moreover, postcontrast T1-WI imaging of the lesion showed a dural tail sign.

A C3 to C5 dorsal laminectomy, durotomy, and mass resection were performed under a surgical microscope. Intraoperatively, the mass appeared to be located inside the dura mater (Fig. 2a). The surrounding cerebrospinal fluid was transparent. The mass was reddish, angiogenic, and slightly harder than the surrounding normal spinal cord tissue. Intraoperative ultrasonic inspection was thus used to reveal the boundaries of the mass (Fig. 2b). The mass was clearly demarcated and slightly hyperechogenic compared with the normal spinal cord. However, the boundaries between the mass and the healthy spinal cord were unclear, when viewed with the surgical microscope. The body of the mass was easily separated from the normal spinal cord, but the cranial and caudal portions of the mass, which had exhibited the dural tail sign in MR imaging, had poor margins.

After recovery from anaesthesia, the animal exhibited laboured breathing and decreased oxygen saturation for $36 \mathrm{~h}$ post-surgery. The dyspnoea was caused by damage to $\mathrm{C} 5-\mathrm{C} 6$, which comprises the phrenic nerve roots and were affected by the surgery [13-15]. A daily dose of prednisolone $1 \mathrm{mg} / \mathrm{kg}$ was prescribed after surgery. The animal's neck pain had apparently improved, and the neurological signs remained unchanged until 1 month postoperatively, at which point the neck pain recurred; laboured breathing and dysuria were also observed at this time. Upper motor neuron paresis was diagnosed as the cause of the dysuria, and the dog could not urinate by itself. Urination was possible by applying pressure to the bladder, which was painful. The laboured breathing gradually worsened. Finally, the dog died at home 42 days postoperatively. The cause of death was thought to be respiratory failure. However, this could not be confirmed because the owner did not permit post-mortem examination.

Histopathologic examination of the mass revealed glial cells with infiltration of neutrophils, macrophages, lymphocytes (Fig. 3a and b). The surgical margin of the excised mass was intralesional such that mixed inflammatory cells were located at the periphery of the mass. The mass was located deep in the pia mater, and S-100(a marker for neuroectodermal origin) and GFAP (a marker for astrocytes)-positive cells were observed in the mass by immunohistochemistry (IHC) (Fig. 3c and d), suggesting that the lesion was located within the spinal cord. Furthermore, the surface of the lesion was covered by pia mater. However, most of the pre-existing spinal tissue, including the pia mater, showed signs of inflammation and some haemorrhage (Fig. 3c and d). Moreover, numerous Iba-1-positive cells (macrophages/ microglia) and CD3- and CD79 $\alpha$-positive cells (T and B lymphocytes, respectively) were observed on IHC (Fig. 4). These cells were positive for $\mathrm{Ki}-67$, a proliferative cell marker (Fig. 4d). Periodic acid-Schiff and Gram and Grocott staining were used to detect the presence of pathogens within the lesion. However, no pathogens were found.

\section{Discussion and conclusions}

In the case described here, imaging and surgery were carried out under the assumption that the patient's space-occupying lesion was a meningioma. However, the lesion was located within the dura mater, as confirmed by intraoperative macroscopic, microscopic, and ultrasonographic examination. Histological findings of the resected mass revealed infiltration of inflammatory cells and a highly immunoreactive cellular mixture of neutrophils, macrophages, and lymphocytic cells. Thus, the first 

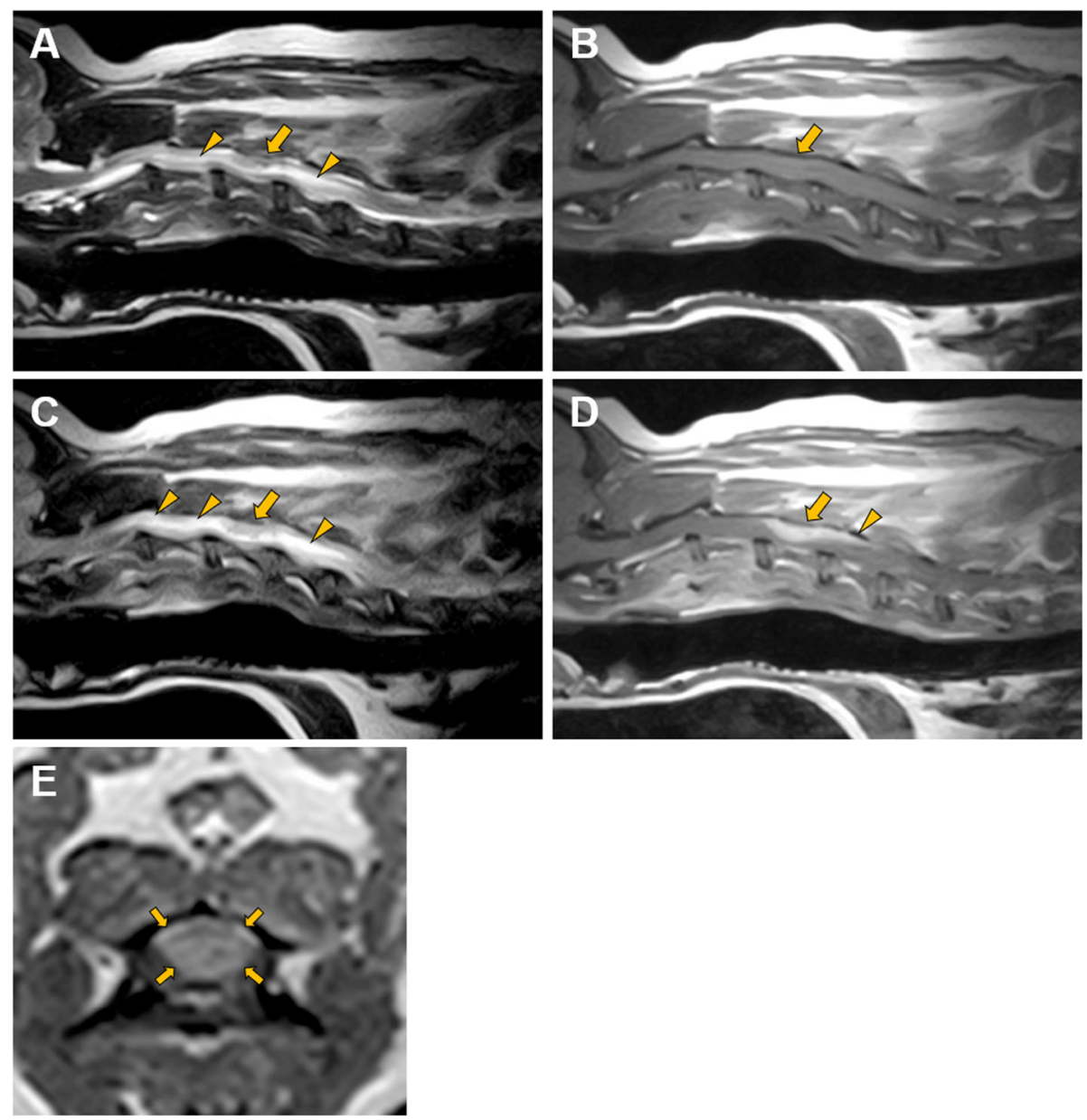

Fig. 1 Magnetic resonance imaging of the intradural mass lesion. Sagittal T2-weighted images reveal a mass in the dorsal spinal cord at the fourth cervical (C4) level (yellow arrow) and a large hyperintense lesion from C2 to C6 (yellow arrowheads) (a). The mass is isointense (yellow arrow), and the area around the mass is isointense (b) on T1-weighted images. The mass is hypo- to isointense (yellow arrow), and the area around the mass is hyperintense on fluid attenuated inversion recovery imaging (yellow arrowheads) (c). The mass is homogenously enhanced (yellow arrow) after contrast administration and shows a dural tail sign (yellow arrow head) on T1-weighted imaging (d). The mass (yellow arrows) is spherical and homogenously enhanced after contrast administration on T1-weighted transverse imaging (e)
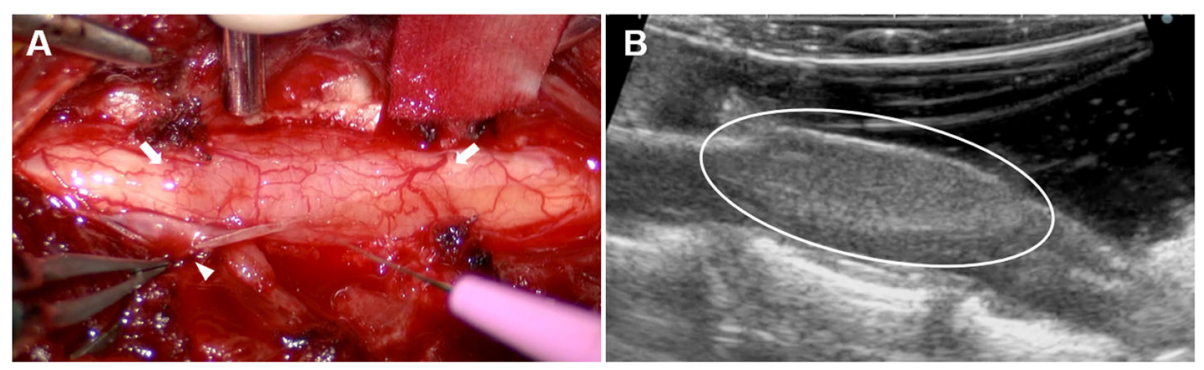

Fig. 2 Intraoperative image of the lesion. The arrowhead indicated the incised dura mater. The dura mater covering the mass is thinner than normal dura mater, and the mass is located within the dura mater. The mass is red, indicating angiogenesis. The boundary between the mass and normal spinal cord tissue is unclear (arrow) (a). Intraoperative ultrasonic inspection shows that the mass is homogenous and hyperintense relative to the normal spinal cord; the boundary between the mass and normal spinal cord can be confirmed (b, circle) 


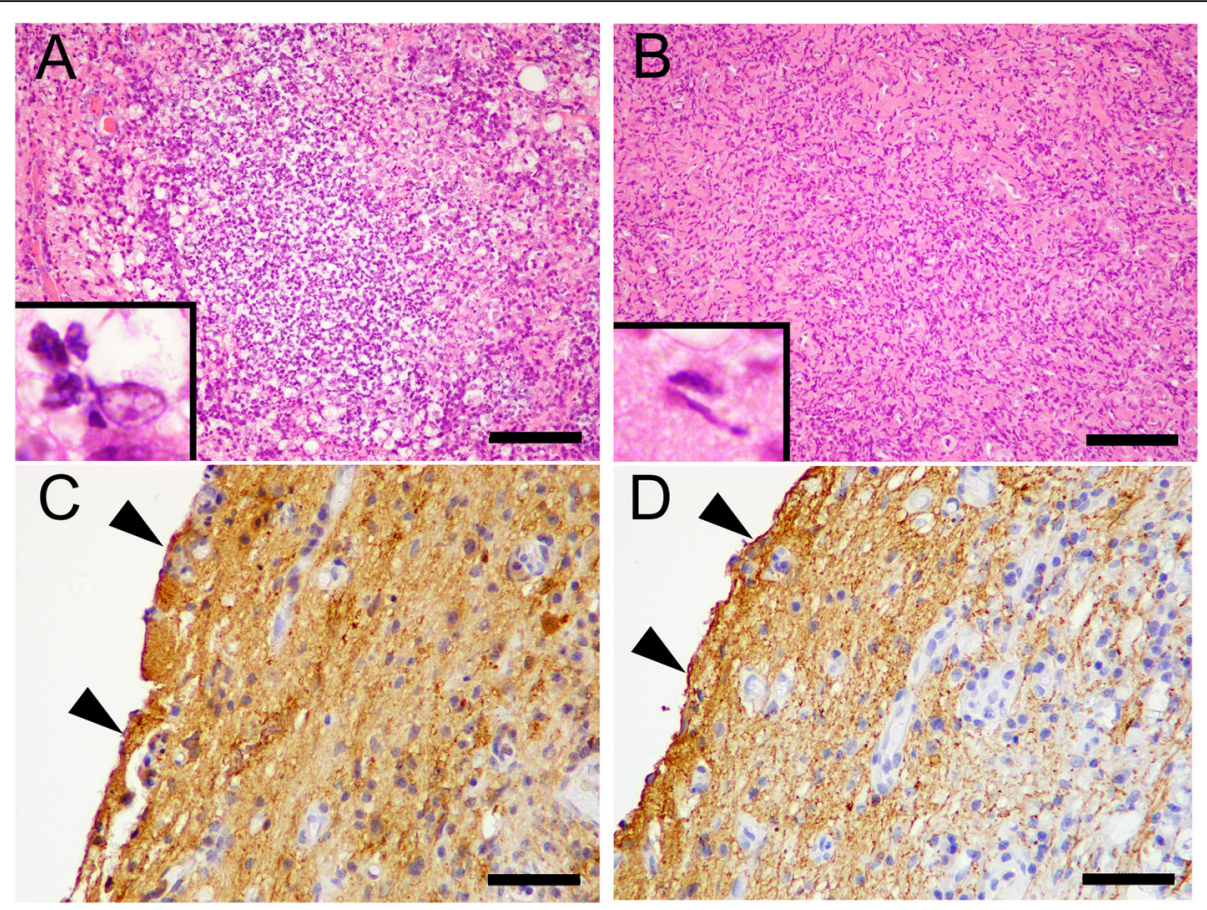

Fig. 3 Histopathological images of the inflammatory pseudotumour. These images reveal a highly cellular mixture of neutrophils, macrophages, and lymphocytes (a; inset shows the nuclei of macrophages and neutrophils) and numerous chromatin-rich, spindle-shaped cells (b, elongated nucleus of activated glial cells). In addition, immunohistochemically- labelled S-100 (nerve cell marker)- and GFAP (astrocytic cell marker)-positive cells are observed within the mass ( $\mathbf{c}$ and $\mathbf{d}$ ). The pia mater (arrowheads in $\mathbf{C}$ and D) is observed on the surface of the mass. Scale bars are $100 \mu \mathrm{m}$ in $\mathrm{A}$ and $\mathrm{B}$ and $50 \mu \mathrm{m}$ in $\mathbf{c}$ and $\mathbf{d}$

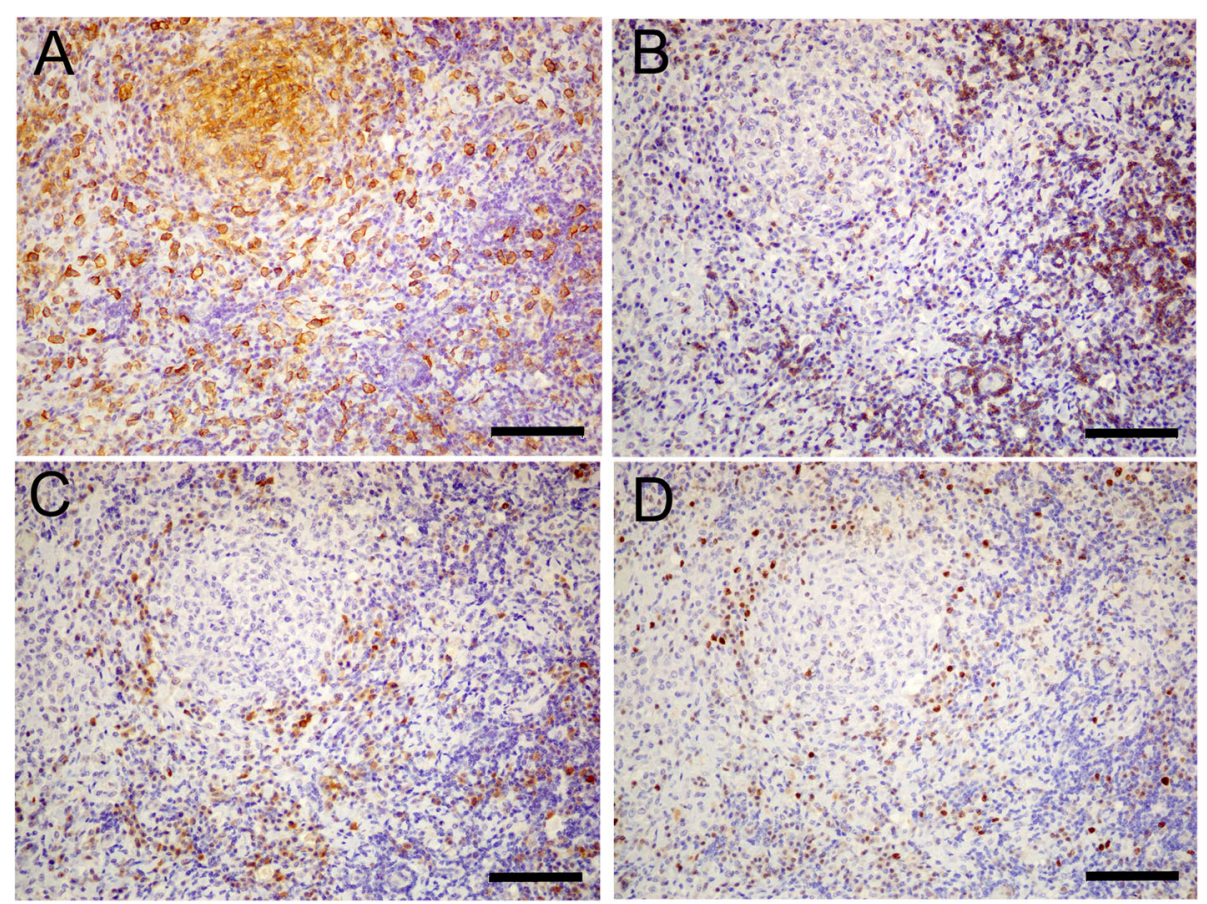

Fig. 4 Immunohistological images of immune cells and a cell proliferation marker in mass tissue. Large amounts of Iba-1 (macrophage marker)positive cells are observed (a); CD3 ( $\mathrm{T}$ lymphocyte marker)- and CD79a (B lymphocyte marker)-positive cells are present (b and $\mathbf{c}$ ), as are Ki-67 (cell proliferation marker)-positive cells (d). Scale bars are $100 \mu \mathrm{m}$ 
diagnosis, meningioma, was discarded after evaluating the intraoperative findings. The mass located within the dura mater was ultimately diagnosed as an IPT of the parenchyma of the spinal cord by histopathological and immunohistochemical findings. The lesion was diagnosed as an extramedullary meningioma before surgery because the dural tail sign was observed on MR imaging; this sign is regarded as a common and useful marker to distinguish meningiomas from other intracranial and spinal lesions [16-18]. However, it has been reported that other tumours, such as glioblastoma, also exhibit the dural tail sign [16].

A clear definition of IPT with regard to diagnostic criteria is not yet available, especially in the veterinary field. However, the clinical and histopathological findings in the present case are consistent with previous reports of IPT. In particular, the following points support the possibility of IPT: 1) mixed inflammatory cells mainly consisting of lymphocytes and plasma cells and 2) proliferation of spindle shaped cells (fibroblasts/myofibroblasts). Empyema, another inflammatory lesion, is an important differential diagnosis. In empyema, the infiltration of neutrophils is a predominant feature, and the condition is often associated with systemic infections, foreign bodies, or trauma $[19,20]$. However, these findings were not observed in the present case.

The MR imaging findings in this case were very similar to those of an earlier intradural extramedullary IPT report [2]. Although we initially presumed that the lesion was extramedullary, it was found within the parenchyma of the spinal cord on histological examination. Since the imaging findings did not differ between the present lesion and previous extramedullary lesions, distinguishing between them was difficult. Thus, it may be necessary to perform a laminectomy, intraoperative ultrasonographic inspection, and histopathological examination to confirm the location of the lesion.

Some researchers have speculated about the aetiology of IPTs. Possible aetiologies include a low-grade inflammatory fibrosarcoma, inflammation following a minor trauma or surgery, an immune-autoimmune mechanism, and pathogenic infection [8,21-25]. Neutrophilic infiltration was remarkable in the histopathological sections in this patient. However, no pathogens or foreign bodies were observed in the excised mass, and the surrounding cerebrospinal fluid was macroscopically transparent. Given these findings, infections and/or trauma were probably not the cause of the IPT. The cause of the IPT in the present case could not be clearly determined. However, Dachshunds have a predisposition to autoimmune reactive diseases such as sterile panniculitis and other adverse events following vaccine administration; thus, the characteristics of the breed could have been related to the occurrence of the IPT in this case $[26,27]$.
The outcome in the present case was not satisfactory, especially when compared to a previous extramedullary IPT, in which a dog exhibited stable neurological signs 2.5 years after initial presentation [2]. Moreover, the outcome of the present case was poorer than that of a case of human intramedullary IPT [2]. Cervical dorsal laminectomy has several complications, including neurological deterioration [28]. Signs of laboured breathing were found after surgery in the present case. We thought that the symptom was a complication of the surgery and was indicative of damage to the spinal cord. Moreover, the phrenic nerve roots were locaed at the surgical approach area $(\mathrm{C} 3-\mathrm{C} 5)$ in this patient $[13,14]$. Injury to the phrenic nerve causes dyspnoea [15], which can be lethal. In this case, the mass invaded the nerve tissue, which led to greater loss of nerve function, than that encountered in other cases of extramedullary IPT. Preoperative nerve damage due to IPT invasion probably increased the severity of surgical complications. We suspect that respiratory failure following laboured breathing was the cause of death, but the source of this recurrence is unclear.

The determination of the location of intra- or extramedullary lesions is crucial for predicting the prognosis of canine spinal cord IPTs. However, MR imaging is often insufficient for distinguishing between intra- and extramedullary lesions. Additional spinal cord IPT investigations are thus required, and exploratory laminectomies may be necessary to diagnose and accurately determine the patient's prognosis.

\section{Abbreviations}

IHC: Immunohistochemistry; IPT: Inflammatory pseudotumour; MR: Magnetic resonance; WI: Weighted imaging

\section{Acknowledgements}

Not applicable.

\section{Authors' contributions}

MY wrote the initial draft of the manuscript. TO and YS contributed to the analysis and interpretation of data, and assisted in the preparation of the manuscript. MY, TO, YS, YM, RM, TI and YO contributed to data collection and interpretation and critically reviewed the manuscript. All the authors have read and approved the final version of the manuscript and agree to be accountable for all aspects of the work in ensuring that questions related to the accuracy or integrity of any part of the work are appropriately investigated and resolved.

\section{Funding}

This research received no specific grant from any funding agency in the public, commercial, or not-for-profit sectors.

\section{Availability of data and materials}

The data are not available for public access because of patient privacy concerns, but are available from the corresponding author on reasonable request.

Ethics approval and consent to participate Not applicable. 


\section{Consent for publication}

Written informed consent was obtained from the patient's owner for the publication of this report and associated images.

\section{Competing interests}

The authors declare that they have no competing interests.

\section{Author details}

'Joint Department of Veterinary Clinical Medicine, Faculty of Agriculture, Tottori University, 4-101 Koyama-cho Minami, Tottori, Tottori 680-8553, Japan. ${ }^{2}$ Ai Doubutsu Clinic, 4-22-28 Higashifukuhara, Yonago, Tottori 683-0802, Japan

Received: 31 May 2019 Accepted: 11 December 2019

Published online: 19 December 2019

\section{References}

1. Coffin CD, Fletcher JA. Inflammatory myofibroblastic tumor. In: Fletcher CD, Unni KK, Mertens F, editors. World Health Organization Classification of Tumours. Pathology and Genetics of Tumours of Soft Tissue and Bone. Lyon: World Health Organization; 2002. p. 91-3.

2. Loderstedt S, Walmsley GL, Summers BA, Cappello R, Volk HA. Neurological, imaging and pathological features of a meningeal inflammatory pseudotumour in a Maltese terrier. J Small Anim Pract. 2010;5:387-92.

3. Gleason BC, Hornick JL. Inflammatory myofibroblastic tumours: where are we now? J Clin Pathol. 2008;61:428-37.

4. Gärtner F, Santos M, Gillette D, Schmitt F. Inflammatory pseudotumour of the spleen in a dog. Vet Rec. 2002;150:697-8.

5. Billson FM, Miller-Michau T, Mould JR, Davidson MG. Idiopathic sclerosing orbital pseudotumor in seven cats. Vet Ophthalmol. 2006;9:45-51.

6. Knight C, Fan E, Riis R, McDonough S. Inflammatory myofibroblastic tumors in two dogs. Vet Pathol. 2009;46:273-6.

7. Böhme B, Ngendahayo P, Hamaide A, Heimann M. Inflammatory pseudotumours of the urinary bladder in dogs resembling human myofibroblastic tumours: a report of eight cases and comparative pathology. Vet J. 2010;183:89-94.

8. Beck A, Špičić S, Butorović-Dujmović M, Račić I, Huber D, Gudan Kurilj A, et al. Mucocutaneous inflammatory pseudotumours in simultaneous Mycobacterium avium subsp. avium and Mycobacterium avium subsp. hominissuis infection in a cat. J Comp Pathol. 2015;153:227-30.

9. Lee M, Epstein FJ, Rezai AR, Zagzag D. Nonneoplastic intramedullary spinal cord lesions mimicking tumors. Neurosurgery. 1998;43:788-94.

10. Kilinç M, Ertürk IO, Uysal H, Birler K, Evrenkaya T, Akkalyoncu BB. Multiple plasma cell granuloma of the central nervous system: a unique case with brain and spinal cord involvement. Case report and review of literature. Spinal Cord. 2002;40:203-6.

11. Boutarbouch M, Arkha Y, Rifi L, Derraz S, El Ouahabi A, El Khamlichi A. Intradural cervical inflammatory pseudotumor mimicking epidural hematoma in a pregnant woman: case report and review of the literature. Surg Neurol. 2008;69:302-5.

12. Ishihara M, Izumoto S, Iwatsuki K, Yoshimine T. Immunohistochemical study of multiple inflammatory pseudotumors with both brain and spinal cord involvement-case report. Neurol Med Chir (Tokyo). 2010;50:246-50.

13. Dellmann HD, McClure RC. Carnivore neurology. In: Sisson S, Grossman DJ, Getty R, editors. Sisson and Grossman's the anatomy of the domestic animals. 5th ed. Philadelphia: W. B. Saunders Co.; 1975. p. 1672-713.

14. Leduc D, De Troyer A. Dysfunction of the canine respiratory muscle pump in ascites. J Appl Physiol (1985). 2007;102:650-7.

15. Bai R, Patel D, Di Biase L, Fahmy TS, Kozeluhova M, Prasad S, et al. Phrenic nerve injury after catheter ablation: should we worry about this complication? J Cardiovasc Electrophysiol. 2006;17:944-8.

16. Guermazi A, Lafitte F, Miaux Y, Adem C, Bonneville J-F, Chiras J. The dural tail sign-beyond meningioma. Clin Radiol. 2005;60:171-88.

17. Hsieh CT, Liu MY, Tang CT, Sun JM, Tsai WC, Hsia CC. Problem of dural tail sign in glioblastoma multiforme? Acta Neurol Belg. 2009;109:320-13.

18. Zhang LH, Yuan HS. Imaging appearances and pathologic characteristics of spinal epidural meningioma. Am J Neuroradiol. 2017:39:199-204.

19. Granger N, Hidalgo A, Leperlier D, Gnirs K, Thibaud JL, Delisle F, et al. Successful treatment of cervical spinal epidural empyema secondary to grass awn migration in a cat. J Feline Med Surg. 2007;9:340-5.
20. De Stefani A, Garosi LS, McConnell FJ, Diaz FJ, Dennis R, Platt SR. Magnetic resonance imaging features of spinal epidural empyema in five dogs. Vet Radiol Ultrasound. 2008;49:135-40.

21. Maves CK, Johnson JF, Bove K, Malott RL. Gastric inflammatory pseudotumor in children. Radiology. 1989;173:381-3.

22. Stark P, Sandbank JC, Rudnicki C, Zahavi I. Inflammatory pseudotumor of the heart with vasculitis and venous thrombosis. Chest. 1992;102:1884-5.

23. Dehner LP. The enigmatic inflammatory pseudotumours: the current state of our understanding, or misunderstanding. J Pathol. 2000;192:277-9.

24. Sanders BM, West KW, Gingalewski C, Engum S, Davis M, Grosfeld JL. Inflammatory pseudotumor of the alimentary tract: clinical and surgical experience. J Pediatr Surg. 2001;36:169-73.

25. Narla LD, Newman B, Spottswood SS, Narla S, Kolli R. Inflammatory pseudotumor. Radiographics. 2003;23:719-29.

26. Moore GE, Guptill LF, Ward MP, Glickman NW, Faunt KK, Lewis HB, et al. Adverse events diagnosed within three days of vaccine administration in dogs. J Am Vet Med Assoc. 2005;227:1102-8.

27. Yamagishi C, Momoi Y, Kobayashi T, Ide K, Ohno K, Tsujimoto H, et al. A retrospective study and gene analysis of canine sterile panniculitis. J Vet Med Sci. 2007:69:915-24

28. Taylor-Brown FE, Cardy TJ, Liebel FX, Garosi L, Kenny PJ, Volk HA, et al. Risk factors for early post-operative neurological deterioration in dogs undergoing a cervical dorsal laminectomy or hemilaminectomy: 100 cases (2002-2014). Vet J. 2015;206:327-31

\section{Publisher's Note}

Springer Nature remains neutral with regard to jurisdictional claims in published maps and institutional affiliations.

\section{Ready to submit your research? Choose BMC and benefit from:}

- fast, convenient online submission

- thorough peer review by experienced researchers in your field

- rapid publication on acceptance

- support for research data, including large and complex data types

- gold Open Access which fosters wider collaboration and increased citations

- maximum visibility for your research: over $100 \mathrm{M}$ website views per year

At BMC, research is always in progress.

Learn more biomedcentral.com/submissions 